\title{
Carcinoma espinocelular de conjuntiva com evolução para exenteração: relato de caso
}

\section{Conjunctival squamous cell carcinoma requiring orbital exenteration: case report}

\author{
Larissa Horikawa Satto ${ }^{1}$, Mariangela Esther Alencar Marques², Silvana Artioli Schellini ${ }^{3}$
}

\section{RESUMO}

Portador de carcinoma espinocelular da conjuntiva teve a lesão removida, com recorrência em outra localização. O paciente recebeu ciclos de 5-Fluoruracila como tratamento adjuvante à remoção cirúrgica, apresentando evolução desfavorável que chegou à exenteração orbitária. São feitos comentários quanto ao uso de antimitó ticos no tratamento destas lesões.

Descritores: Neoplasias de células escamosas; Neoplasias da túnica conjuntiva; Recidiva local de neoplasia; Exenteração orbitária; Fluoruracila/administração \& dosagem; Fluoruracila/uso terapêutico; Antimitóticos/uso terapêutico; Humanos; Masculino; Meia idade

\begin{abstract}
A case of a squamous cell carcinoma of the conjunctiva is presented. The lesion was removed with recurrence in another conjunctival site. The patient received cycles of 5-Fluorouracil as adjuvant treatment to the surgical removal and presented unfavorable evolution, requiring orbital exenteration. Comments are made on the use of antimitotic drugs in the management of these lesions.
\end{abstract}

Keywords: Neoplasms, squamous cell; Conjunctival neoplasms; Neoplasm recurrence, local; Orbit exenteration; Fluorouracil/administration \& dosage; Fluorouracil therapeutic use; Antimitotic agents/therapeutic use; Humans; Male; Middle aged

\section{INTRODUÇÃO}

O carcinoma espinocelular da conjuntiva (CEC) é o tumor maligno mais comum da conjuntiva ${ }^{(1)}$. Possui etiologia multifatorial ${ }^{(2,3)}$ idade avançada ${ }^{(4)}$, exposição a raios ultravioleta ${ }^{(4,5)}$, e a derivados do petróleo, fumaça de cigarro, infecção pelo papilomavírus humano $(\mathrm{HPV})^{(5)}$, e pelo vírus da imunodeficiência humana (HIV).

O CEC conjuntival possui baixo grau de malignidade, facilmente identificável, raramente leva à metástase e responde muito bem à excisão cirúrgica; entretanto, pode haver recorrência, o que o torna mais agressivo(6).

A terapia de escolha é a excisão cirúrgica, sendo a ressecção incompleta o maior fator de risco para o insucesso terapêutico ${ }^{(4)}$. Outras causas de recidiva seriam a semeadura de células tumorais no momento da exérese, surgimento da lesão "de novo" ou recidiva ${ }^{(1)}$.

Tratamentos adjuvantes como crioterapia, radiação e antimetabólicos têm sido empregados para reduzir a recidiva, como terapia primária ou adjuvante.

O objetivo deste relato de caso é apresentar um portador de CEC tratado por exérese da lesão e aplicação tópica de 5-fluoruracila (5-FU) e que evoluiu de forma desfavorável, discutindo os fatos à luz da literatura pertinente.

\section{RELATO DO CASO}

Masculino, 68 anos, pardo, procedente de Cerquilho/SP, foi atendido na Faculdade de Medicina de Botucatu (UNESP) em agos- to/2005, com queixa de nódulo indolor no olho esquerdo (OE), prurido intenso e lacrimejamento. Negava outros sintomas visuais ou sistêmicos, não possuía antecedentes oculares e relatava hipertensão arterial, diabetes mellitus e gastrite.

Ao exame oftalmológico, acuidade visual (AV) corrigida era 20/60 no olho direito (OD) e 20/40 no OE; pressão intraocular por tonometria de aplanação era $12 \mathrm{mmHg} O \mathrm{O}$ e $14 \mathrm{mmHg}$ OE. À biomicroscopia observou-se lesão conjuntival de aspecto papilomatoso, elevada, vascularizada, invadindo a córnea, com concreções em sua superfície, localizada no limbo temporal OE (Figura 1).

Suspeitou-se de CEC, procedendo-se à exérese com aplicação intraoperatória de 5-FU. O diagnóstico anatomopatológico confirmou CEC moderadamente diferenciado, com margens cirúrgicas livres (Figura 2). O paciente foi reencaminhado para acompanhamento na cidade de origem.

Em setembro/2006, apresentou nova lesão no OE há 15 dias, em local diferente da lesão prévia. A biomicroscopia evidenciou lesão elevada, com superfície lisa e coloração amarelada, localizada na região nasal superior $\mathrm{OE}$. Realizada biópsia, com resultado de CEC. Foi introduzido ciclo de 5 -FU $25 \mathrm{mg} / \mathrm{ml}$, três vezes ao dia, durante sete dias e programada cirurgia para exérese que não foi realizada, por ter ocorrido regressão da lesão. Realizado raspado conjuntival, tendo como resultado a presença de células epiteliais com atipias discretas, inconclusivo para malignidade.

Novo ciclo de 5-FU tópico foi realizado, com acompanhamento ambulatorial mensal.

Pathologist, Departamento de Patologia, Faculdade de Medicina, Universidade Estadual de São

Funding: No specific financial support was available for this study Disclosure of potential conflicts of interest: L.H.Satto, None; M.E.A.Marques, None; S.A.Schellini, None.

Correspondence Address: Silvana Artioli Schellini. DEP. OFT/ORL/CCP. Faculdade de Medicina de Botucatu - UNESP - Botucatu (SP) - 18618-970 - Brazil - E-mail: sartioli@fmb.unesp.br 


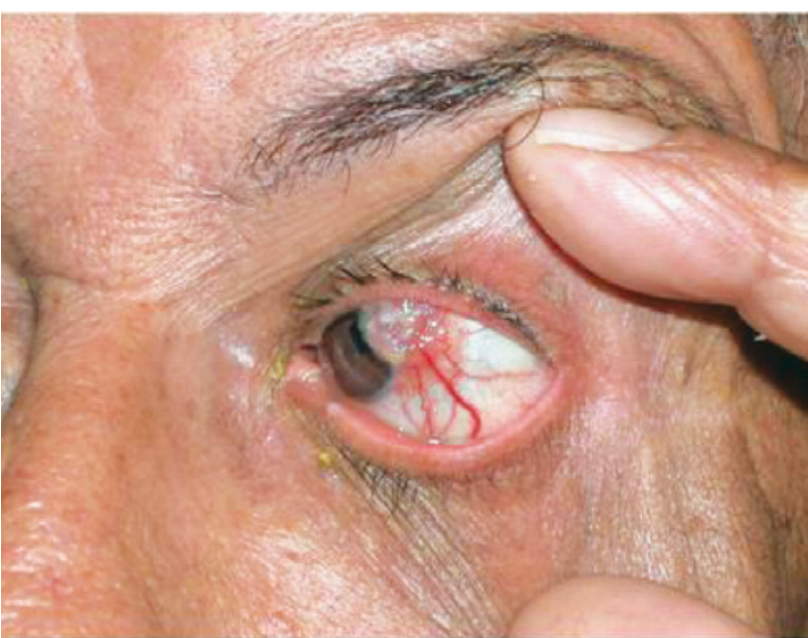

Figura 1. Aspecto ectoscópico do carcinoma espinocelular da conjuntiva, localizado no limbo temporal do olho esquerdo, no início do tratamento.

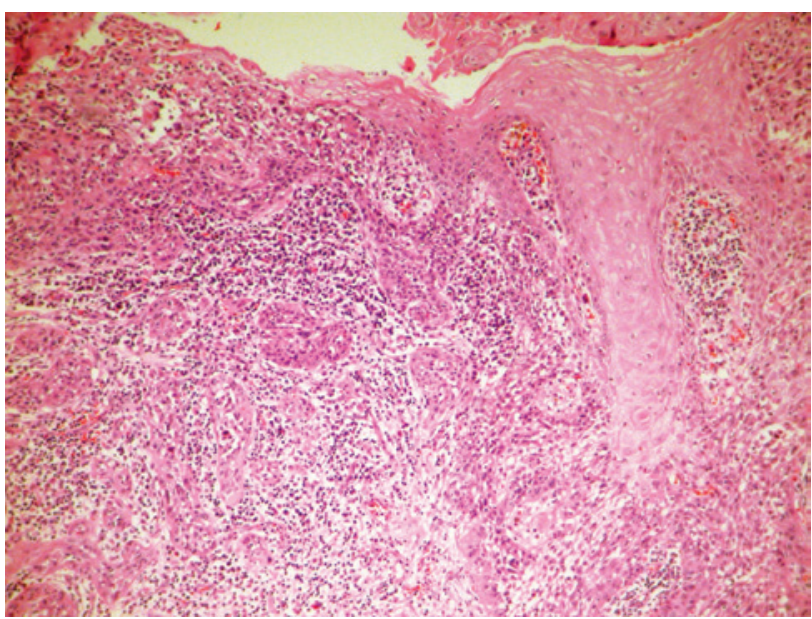

Figura 2. Carcinoma espinocelular da conjuntiva ulcerado e moderadamente diferenciado (HE200X).

Dois meses após o raspado conjuntival e na vigência do uso do 5-FU, houve novo crescimento da lesão de aspecto esponjoso, na região nasal superior $\mathrm{OE}$. O antimitótico foi mantido por mais dois meses, em esquema regressivo, tendo novamente ocorrido regressão da lesão conjuntival.

Três meses depois, o paciente retorna com abaulamento conjuntival próximo ao fundo-de-saco superior, com coloração amarelada e presença de neovasos. O antimitótico foi intensificado.

Em março/2007, a lesão apresentava-se difusa, acometendo todo o limbo nasal e avançando sobre a córnea, com aspecto de CEC in situ. Após um mês, a lesão parecia estável, apesar do uso do antimitótico.

Optou-se por nova exérese, realizada em junho/2007, com diagnóstico anatomopatológico de CEC, com margens profundas acometidas. Em setembro/2007, evidenciou-se novamente lesão elevada no mesmo local. Feito biópsia excisional, com resultado de conjuntivite aguda supurativa, sem sinais de neoplasia. Solicitada revisão da lâmina ao serviço de Patologia, o qual manteve o diagnóstico.

Em dezembro/2007, verificou-se presença de lesão elevada, extensa, irregular, com algumas áreas hiperpigmentadas, na conjuntiva nasal OE, ocupando todos os fundos-de-saco conjuntivais e avançando sobre a córnea (Figura 3).

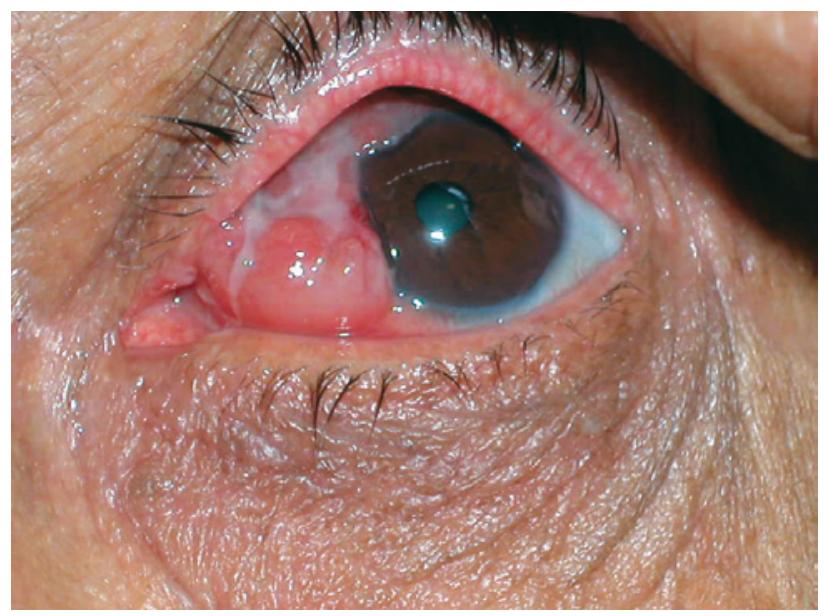

Figura 3. Aspecto da lesão conjuntival recorrente, localizada no limbo nasal antes da exenteração orbitária. A lesão agora acometia toda a região nasal e chegava até os fundos-de-saco.

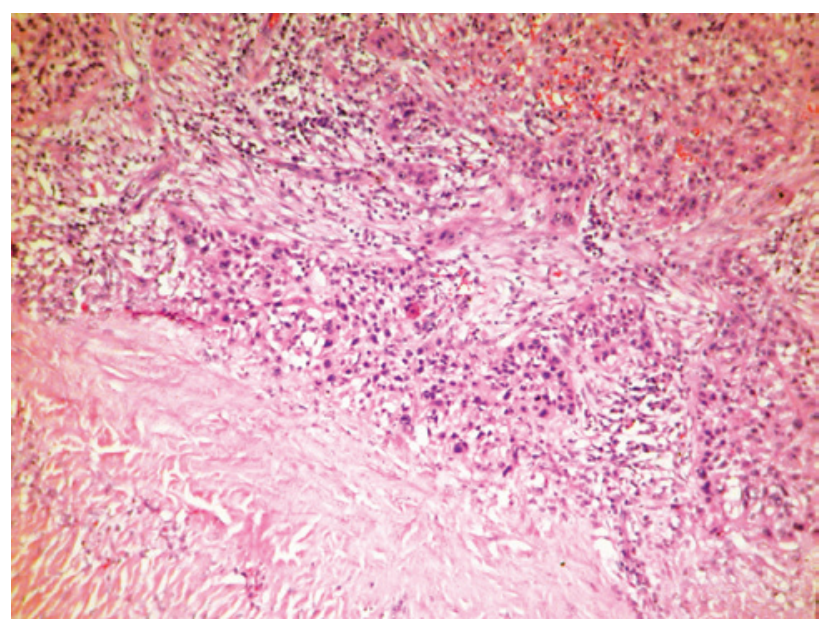

Figura 4. Carcinoma espinocelular da conjuntiva pouco diferenciado com invasão da esclera (HE200X).

Indicado uso de 5-FU enquanto era feito "screening" para avaliação de acometimento sistêmico e infiltração local, usando tomografia computadorizada de órbita e ultrassonografia cervical, que não revelaram comprometimento das estruturas avaliadas, exceto do osso etmoide.

Optou-se pela exenteração orbitária, removendo-se o osso etmoide. O exame anatomopatológico revelou CEC ulcerado, pouco diferenciado, com atipias celulares intensas, mitoses frequentes e raras células queratinizadas com infiltração superficial da esclera (Figuras 4 e 5).

Decorridos três anos, o paciente encontra-se em seguimento e bem. Foi feita a adaptação de prótese de face, com boa reabilitação estética.

\section{DISCUSSÃO}

O paciente em questão apresentava as características dos portadores de lesões epiteliais malignas da conjuntiva com lesão típica, que foi removida e tinha margens cirúrgicas livres do tumor. No entanto, houve recorrência do tumor em outro local, com características clínicas diversas da primeira. 


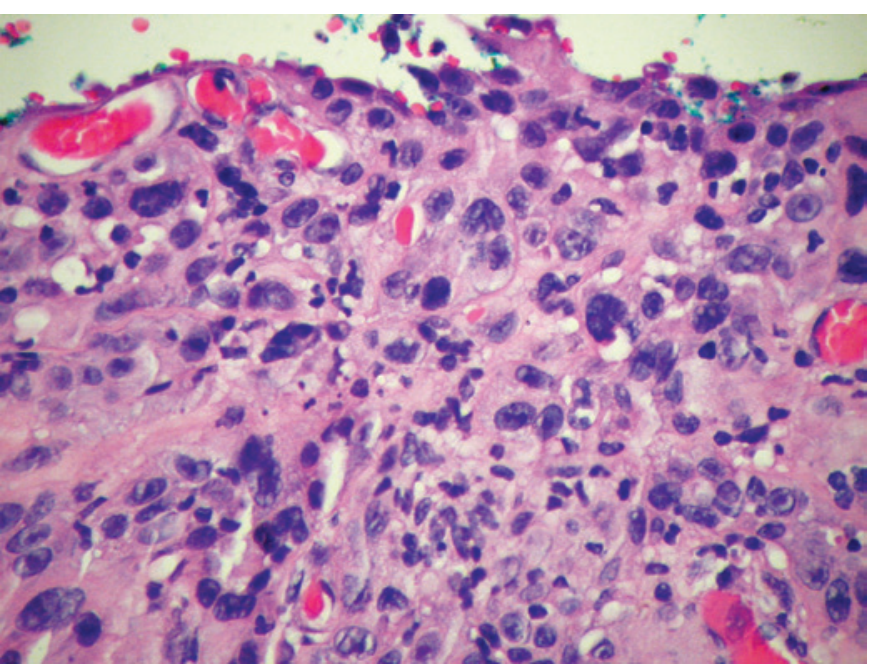

Figura 5. Carcinoma espinocelular da conjuntiva pouco diferenciado, comatipias celulares intensas, mitoses frequentes e raras células queratinizadas (HE400X).

A possibilidade de recidiva ou de recorrência reforça a necessidade de revisões periódicas, mesmo que as margens cirúrgicas estejam livres do tumor, já que margens não acometidas não garantem a cura(1).

O uso de quimioterápicos tópicos, como o 5-FU, a mitomicina C (MMC) e o interferon Alfa-2b (IFN) tem sido feito como terapia adjuvante ou única para tratamento de tumores da conjuntiva. Entetanto, o paciente apresentou novas lesões após ter tido a regressão da lesão sob uso de 5-FU.

A MMC é um agente antitumoral que inibe a síntese de DNA $A^{(2)} \mathrm{e}$ tem capacidade para erradicar células tumorais. Bons resultados têm sido obtidos, tanto com a terapia adjuvante, quanto com uso isolado, em doença primária e recorrente ${ }^{(6)}$.

O 5-FU é uma droga citostática e de ação antimetabólica, com potencial de toxicidade seletiva para o epitélio displásico. O uso do colírio de 5-FU 1\%, quatro vezes ao dia, durante quatro semanas pode levar à regressão clínica da lesão, como também pudemos evidenciar, com substituição da lesão por epitélio normal; porém, existe risco de recidiva e de ceratoconjuntivite tóxica ${ }^{(7)}$, muito mais frequente e mais importante com o uso da MMC, o que motiva o uso do 5-FU no nosso serviço.

O 5-FU apresenta diversas vantagens quando comparado com a excisão cirúrgica(8): trata toda a superfície ocular, eliminando a necessidade de garantir margens cirúrgicas livres; reduz o risco de deficiência de células tronco que ocorre nas excisões extensas envolvendo o limbo corneano; simplicidade do tratamento e custo reduzido, evitando repetições da cirurgia quando há recorrência. Como desvantagens, são relatadas ${ }^{(2,3)}$ : penetração limitada com potencial falha no tratamento quando usada como agente único no CEC invasivo; potencial para mudanças no epitélio da nasofaringe; efeitos colaterais locais, como desconforto conjuntival e hiperemia, ceratopatia epitelial ponteada e blefaroespasmo.
O IFN por via tópica, subconjuntival ou combinação destas é eficiente no tratamento de lesões primárias e recidivadas ${ }^{(9,10)}$. O mecanismo de ação não é conhecido, mas pode envolver uma combinação de efeitos antiproliferativo e antiviral contra o HPV. O uso tópico é bem tolerado, mas febre e mialgia podem ocorrer com o uso subconjuntival ${ }^{(10)}$.

Os quimioterápicos tópicos podem alterar a aparência clínica e histológica das células epiteliais, dificultando o diagnóstico, o que pode ter ocorrido no presente caso.

O antimitótico pode levar à regressão da lesão, o que foi confirmado pelo exame histológico no caso aqui relatado.

A lesão do paciente quando da última recidiva não era típica, com acometimento extenso, chegando até os fundos-de-saco, sinal de prognóstico sombrio. A investigação sistêmica e local mostrou que seria ainda possível a exenteração, conduta agressiva, mas que se fez necessária. Apesar da grande morbidade ocasionada pelo procedimento realizado, a vida do paciente está preservada.

É importante ainda salientar que o acompanhamento do paciente deve ser criterioso, já que recidivas ou novos tumores poderão ocorrer.

\section{CONCLUSÕES}

O CEC conjuntival é facilmente identificável e tratável. Recidivas podem ocorrer, mesmo quando as margens cirúrgicas não estão acometidas. Os antimitóticos, como o 5-FU, podem ser usados como tratamento único ou adjuvante à remoção cirúrgica. Os pacientes devem ter acompanhamento criterioso, sendo necessários, mais estudos, incluindo maior número de pacientes e maior tempo de seguimento, a fim de verificar a real eficácia dos antimitóticos no tratamento do CEC conjuntival.

\section{REFERÊNCIAS}

1. Schellini SA, Matai O, Shiratori C, Marques ME, Junior BO, Padovani CR. Lesões epiteliais malignas da conjuntiva e recidiva tumoral - estudo retrospectivo. Rev Bras Oftalmol. 2005;64(2):71-6.

2. Basti S, Macsai MS. Ocular surface squamous neoplasia: a review. Cornea. 2003;22(7): 687-704.

3. Lee GA, Hirst LW. Ocular surface squamous neoplasia. Surv Ophthalmol. 1995;39(6): 429-50.

4. Bessa HJ, Potting MH, Bomfim MG. Neoplasias conjuntivais. Rev Bras Oftalmol. 1997; 56(10):765-7

5. Palazzi MA, Erwenne CM, Villa LL. Detection of human papillomavirus in epithelial lesions of the conjunctiva. São Paulo Med J. 2000;118(5):125-30.

6. Akpek EK, Ertoy D, Kalyci D, Hasipiri H. Postoperative topical mitomycin C in conjunctival squamous cell neoplasia. Cornea. 1999;18(1):59-62.

7. Midena E, Angeli CD, Valenti M, de Belvis V, Boccato P. Treatment of conjunctiva squamous cell carcinoma with topical 5-fluorouracil. Br J Ophthalmol. 2000;84(3):268-72.

8. Yamamoto N, Ohmura T, Suzuki H, Shirasawa H. Successful treatment with 5-Fluorouracil conjunctival intraepithelial neoplasia refractive to mitomycin-C. Ophthalmology. 2002;109(2):249-52. Comment in: Ophthalmology. 2003;1 10(6):1262-3; author reply 1263. Ophthalmology. 2003;110(4):625-6; author reply 626. Ophthalmology. 2003;110(7):1289.

9. Sturges A, Butt AL, Lai JE, Chodoshy J. Topical interferon or surgical excision for the management of primary ocular surface squamous neoplasia. Ophthalmology. 2008; 115(8):1297-302.

10. Vann RR, Karp CL. Perilesional and topical interferon Alfa-2b for conjunctival and corneal neoplasia. Ophthalmology. 1999;106(1):91-7. Comment in: Ophthalmology. 1999; 106(9):1642-3. 